\title{
Colonic xanthoma: a rare non-neoplastic polypoid lesion
}



Fig. 1 Endoscopic image in a 78-year-old man, with a history of hyperlipidemia and a positive fecal occult blood test, showing a whitish-yellow polyp in the sigmoid colon.

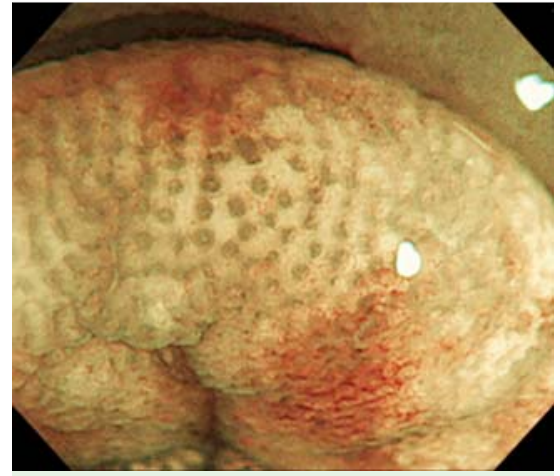

Fig. 2 Magnifying endoscopy with narrow band imaging showing a regular arrangement of small round pits on the surface of the polyp and a vascular pattern of the previously invisible microvessels.

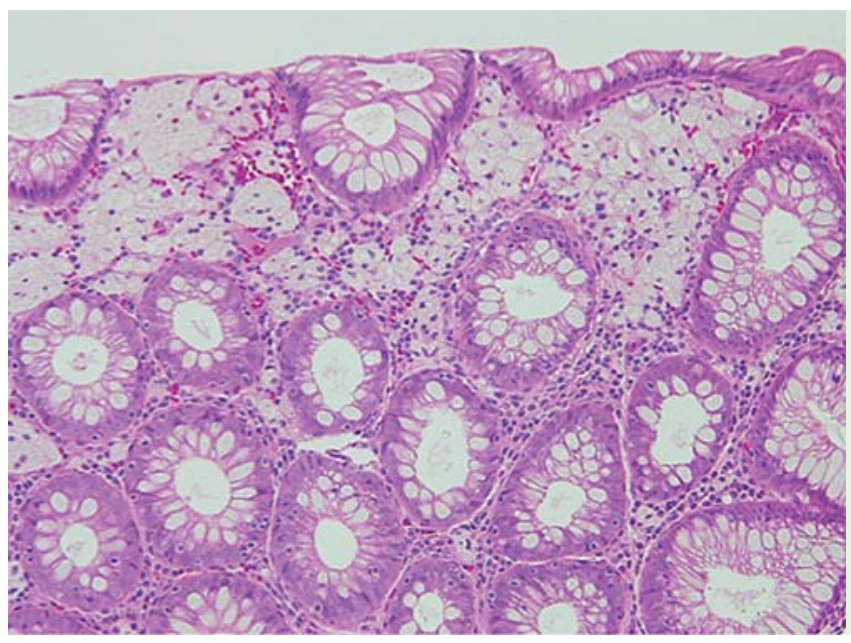

Fig. 3 Histological appearance of the biopsy specimen showing aggregates of foamy histiocytes present in the lamina propria consistent with a xanthoma (hematoxylin and eosin [H\&E] stain, magnification $\times 200$ ).
A 78-year-old man with a history of hyperlipidemia underwent colonoscopy because of a positive fecal occult blood screening test without any symptoms. In the sigmoid colon, a whitish-yellow, sessile, polypoid lesion was found, which measured about $15 \mathrm{~mm}$ in diameter ( Fig.1). Magnifying endoscopy with narrow band imaging revealed a regular arrangement of round pits and previously invisible microvessels on the surface of the mucosa ( $\bullet$ Fig. 2 ).

Endoscopic biopsy specimens revealed an intact superficial colonic mucosa and a lamina propria that was replaced by aggregates of foamy histiocytes. These had small, centrally located nuclei and abun- dant cytoplasm that was filled with fine vacuoles ( Fig.3). Based on these findings, a diagnosis of colonic xanthoma was made, but no additional treatment was administered. We could find no esophageal or gastric xanthoma on esophagogastroduodenoscopy. Repeat colonoscopy performed 1 year later showed no change in appearance of the colonic xanthoma. Gastrointestinal xanthomas are frequently found in the stomach, and rarely, in the esophagus, small bowel, colon, and rectum. Nakasono et al. showed that colonic xanthomas were usually located in the sigmoid colon or rectum and, in contrast to gastric and esophageal xanthomas, consisted of predominantly sessile pol- ypoid lesions [1]. Most were reddish or whitish in color, and the median size was approximately $5 \mathrm{~mm}$ (range $2-14 \mathrm{~mm}$ ). Although xanthomas found in the stomach are usually associated with Helicobacter pylori infection, colonic xanthomas have no clinical significance and their etiology remains unclear [2].

Colonic xanthomas have rarely been described and endoscopic images of them, to our knowledge, have previously been shown in only one case [3]. Our case highlights the characteristic endoscopic appearance of a colonic xanthoma, which is usually regarded as a rare non-neoplastic polypoid lesion.

Endoscopy_UCTN_Code_CCL_1AD_2AC

Competing interests: None

\section{Masaki Katsurahara', Noriyuki Horiki ${ }^{1}$, Shunsuke Tano', Yasuhiko Hamada', Kyosuke Tanaka', Hiroyuki Inoue ${ }^{2}$, Yoshiyuki Takei $^{2}$}

${ }^{1}$ Department of Endoscopic Medicine, Mie University Graduate School of Medicine, Mie, Japan

${ }^{2}$ Department of Gastroenterology and Hepatology, Mie University Graduate School of Medicine, Mie, Japan

\section{References}

1 Nakasono $M$, Hirokawa $M$, Muguruma $N$ et al. Colorectal xanthomas with polypoid lesion: report of 25 cases. APMIS 2004; 112: $3-10$

2 Moran AM, Fogt F. 70-year-old female presenting with rectosigmoid (colonic) xanthoma and multiple benign polyps - case report. Pol J Pathol 2010; 1: $42-45$

3 Weinstock LB, Shartz BA, Saltman RJ et al. Xanthoma of the colon. Gastrointest Endosc 2002; 55: 410

\section{Bibliography}

DOI http://dx.doi.org/

10.1055/s-0033-1359118

Endoscopy 2014; 46: E53

(c) Georg Thieme Verlag KG

Stuttgart · New York

ISSN 0013-726X

\section{Corresponding author}

\section{Masaki Katsurahara, MD, PhD}

Department of Endoscopic Medicine

Mie University Graduate School of Medicine

2-174 Edobashi

Tsu, Mie

Japan

Fax: +81-59-2315223

mkatura@clin.medic.mie-u.ac.jp 